\title{
The force-field of the present model
}

The total energy $U$ in the present model is composed of following eight components $[1,2]$

$$
U=U_{b}+U_{a}+U_{d}+U_{e x c}+U_{b p}+U_{b s}+U_{c s}+U_{e l}
$$

The first three terms are bonded potential for virtual bonds $U_{b}$, bond angles $U_{a}$ and dihedrals $U_{d}$, which are used to mimic the connectivity and the local geometry of RNAs.

$$
\begin{gathered}
U_{b}=\sum_{\text {bonds }} K_{b}\left(r-r_{0}\right)^{2} ; \\
U_{a}=\sum_{\text {angles }} K_{\theta}\left(\theta-\theta_{0}\right)^{2} ; \\
U_{d}=\sum_{\text {dihedrals }}\left\{K_{\varphi}\left[1-\cos \left(\varphi-\varphi_{0}\right)\right]+\frac{1}{2} K_{\varphi}\left[1-\cos 3\left(\varphi-\varphi_{0}\right)\right]\right\},
\end{gathered}
$$

where $K_{b}, K_{\theta}$, and $K_{\varphi}$ represent the energy strength; $r_{0}, \theta_{0}$, and $\varphi_{0}$ are the distances and angles for virtual bonds, bond angles and dihedrals at energy minimum, respectively. The initial parameters of these three potentials were derived from the Boltzmann inversion of the corresponding atomistic distribution functions obtained by the statistical analysis on the experimental structures in the PDB (http://www.rcsb.org/pdb/home/home.do). To well simulate RNA folding approximated as a free chain, we use the parameters, termed as Para $a_{\text {nonhelical, }}$ which is obtained from the single-strands/loops (nonhelical parts) in experimental structures. In structure refinement, another parameter, termed as

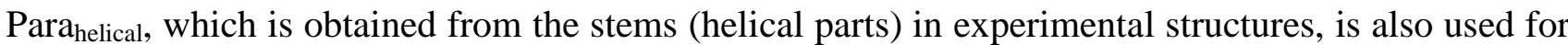
base paired nucleotides of the native-like structure predicted from the folding process.

$U_{\text {exc }}$ in Eq. S1 represents the excluded volume interaction between the $\mathrm{CG}$ beads and it is modeled by a purely repulsive Lennard-Jones potential:

$$
U_{e x c}=\sum_{i<j}^{N} \begin{cases}4 \varepsilon\left[\left(\frac{\sigma_{0}}{r_{i j}}\right)^{12}-\left(\frac{\sigma_{0}}{r_{i j}}\right)^{6}\right] & \text { if } r_{i j} \leq \sigma_{0} \\ & \text { if } r_{i j}>\sigma_{0}\end{cases}
$$

where $\varepsilon=0.26 \mathrm{kcal} / \mathrm{mol}$ is the interaction strength, $\sigma_{0}$ is the sum of the radii of bead $i$ and $j$, and $r_{i j}$ is the distance between bead $i$ and $j$.

$U_{b p}$ in Eq. $\mathrm{S} 1$ is the orientation-dependent base-pairing interaction between bases in the canonical Watson-Crick base pairs (G-C and A-U) and the wobble base pairs (G-U). The potential is 
given by

$$
U_{b p}=\sum_{i<j-3}^{N_{b p}} \frac{\varepsilon_{b p}}{1+k_{N N}\left(r_{N_{i} N_{j}}-r_{N N}\right)^{2}+k_{C N} \sum_{i(j)}\left(r_{C_{i} N_{j}}-r_{C N}\right)^{2}+k_{P N} \sum_{i(j)}\left(r_{P_{i} N_{j}}-r_{P N}\right)^{2}},
$$

where $\varepsilon_{b p}$ is the interaction strength $\varepsilon_{A U}=\varepsilon_{G U}=0.5 \varepsilon_{G C}$ and $\varepsilon_{G C}=-3.5 \mathrm{kcal} / \mathrm{mol}$ in the present model. $r_{N N}, r_{C N}$, and $r_{P N}$ are three distances between the corresponding atoms of $\mathrm{P}, \mathrm{C}$ and $\mathrm{N}$ in two paired nucleotides to determine whether the base-pair is well formed, and $k_{N N}, k_{C N}$ and $k_{P N}$ are the corresponding energy strength.

$U_{b s}$ in Eq. S1 is the base-stacking interaction between two nearest neighbour base pairs, and the energy is given by

$$
U_{b s}=\frac{1}{2} \sum_{i, j}^{N_{s t}}\left|G_{i, i+1, j-1, j}\right|\left\{\left[5\left(\frac{\sigma_{s t}}{r_{i, i+1}}\right)^{12}-6\left(\frac{\sigma_{s t}}{r_{i, i+1}}\right)^{10}\right]+\left[5\left(\frac{\sigma_{s t}}{r_{j, j-1}}\right)^{12}-6\left(\frac{\sigma_{s t}}{r_{j, j-1}}\right)^{10}\right]\right\},
$$

where $\sigma_{s t}$ is the optimum distance of two neighbour bases in the known helix structures. $G_{i, i+1, j-1, j}$ in Eq. S7 is the strength of base-stacking energy and can be estimated from the combination of the experimental thermodynamics parameters [3] and Monte Carlo simulations:

$$
G_{i, i+1, j-1, j}=\Delta H-T\left(\Delta S-\Delta S_{c}\right) ;
$$

more details can be found in our related works $[1,2]$.

$U_{c s}$ in Eq. S1 is the coaxial-stacking between the base-pairs which are the interfaces of two discontinuous neighbour helices:

$$
U_{c S}=\frac{1}{2} \sum_{i-j, k-l}^{N_{c s t}}\left|G_{i, k, l, j}\right|\left\{\left[1-e^{-a\left(r_{i k}-r_{c s}\right)}\right]^{2}+\left[1-e^{-a\left(r_{j l}-r_{c s}\right)}\right]^{2}-2\right\} .
$$

$G_{i, k, l, j}$ is the sequence-dependent base-stacking strength, which is approximately taken as the stacking strength between the corresponding nearest-neighbour base-pairs in an uninterrupted helix [2,3]. $r_{i k}$ (or $r_{j l}$ ) is the distance between two interfaced bases $i(j)$ and $k(l)$ of two stems and $a$ represents the extent of distance constraint. $r_{c s}$ is the optimum distance between two coaxially stacked stems, which is directly obtained from the statistical analysis on the known structures in PDB.

$U_{e l}$ in Eq. S1 is the electrostatic interaction between phosphates with reduced charges given by the Debye-Hückel approximation [1,4]:

$$
U_{e l}=\sum_{i<j}^{N_{P}} \frac{(Q e)^{2}}{4 \pi \varepsilon_{0} \varepsilon(T) r_{i j}} \mathrm{e}^{-\frac{r_{i j}}{l_{D}}}
$$

where $e$ is the elementary charge and $N_{\mathrm{P}}$ is the number of phosphate beads in an RNA. $l_{\mathrm{D}}$ is Debye 
length, which defines the ionic screening. Based on the counterion condensation theory [4] and the tightly bound ion model [5-7], the reduced charge fraction $Q$ could be written as $Q=\frac{b}{v l_{B}}$ for pure ion monovalent $(v=1)$ or divalent $(v=2)$ ion solutions and $Q=f_{\mathrm{Na}^{+}}\left(\frac{b}{l_{B}}\right)+\left(1-f_{\mathrm{Na}^{+}}\right)\left(\frac{b}{2 l_{B}}\right)$ for mixed $\mathrm{Na}^{+} / \mathrm{Mg}^{2+}$ solutions, where $b$ is the charge spacing on RNA backbone, $l_{B}$ is the Bjerrum length, $f_{\mathrm{Na}}{ }^{+}$ and $1-f_{\mathrm{Na}}{ }^{+}$are the contribution fraction from $\mathrm{Na}^{+}$and $\mathrm{Mg}^{2+}$, respectively. The empirical formula

$$
f_{\mathrm{Na}^{+}}=\frac{\left[\mathrm{Na}^{+}\right]}{\left[\mathrm{Na}^{+}\right]+x\left[\mathrm{Mg}^{2+}\right]}
$$

derived by the tightly bound ion model is used for mixed divalent/monovalent ion solutions, and $x=(8.1-64.8 / N)\left(5.2-\ln \left[\mathrm{Na}^{+}\right]\right)$, where $\left[\mathrm{Na}^{+}\right]$and $\left[\mathrm{Mg}^{2+}\right]$ are the corresponding concentrations in molar (M) and $N$ is the chain length [5,7].

The parameters of the above described potentials listed in Table A are derived through the statistical analysis on the known structures and the comparisons between the predictions by the model and the experimental data (see more details in Ref. 1). All the parameters are the same as the previous version of our model $[1,2]$. 
Table A. The parameters of potentials in Eqs. S2-S10.

\begin{tabular}{|c|c|c|c|c|}
\hline \multicolumn{5}{|c|}{ Bond $U_{b}$} \\
\hline & \multicolumn{2}{|c|}{$K_{b}\left(\mathrm{kcal} / \mathrm{mol} / \AA^{2}\right)$} & \multicolumn{2}{|c|}{$r_{0}(\AA)$} \\
\hline & Para $_{\text {helical }}{ }^{a}$ & Para $_{\text {nonhelical }} b$ & Para $_{\text {helical }}{ }^{a}$ & Para $_{\text {nonhelical }} b$ \\
\hline $\mathrm{P}_{i} \mathrm{C}_{i}$ & 133.4 & 98.2 & 3.95 & 3.95 \\
\hline $\mathrm{C}_{i} \mathrm{P}_{i+1}$ & 75.0 & 42.5 & 3.93 & 3.93 \\
\hline $\mathrm{C}_{i} \mathrm{~N}_{i}$ & 85.6 & 24.8 & 3.35 & 3.45 \\
\hline \multicolumn{5}{|c|}{ Angle $U_{a}$} \\
\hline & \multicolumn{2}{|c|}{$K_{\theta}\left(\mathrm{kcal} / \mathrm{mol} / \mathrm{rad}^{2}\right)$} & \multicolumn{2}{|c|}{$\theta_{0}(\mathrm{rad})$} \\
\hline & Para $_{\text {helical }}{ }^{a}$ & Para $_{\text {nonhelical }} b$ & Para $_{\text {helical }}{ }^{a}$ & Para $_{\text {nonhelical }} b$ \\
\hline $\mathrm{P}_{i} \mathrm{C}_{i} \mathrm{P}_{i+1}$ & 18.3 & 9.3 & 1.74 & 1.75 \\
\hline $\mathrm{C}_{i-1} \mathrm{P}_{i} \mathrm{C}_{i}$ & 43.9 & 21.3 & 1.76 & 1.78 \\
\hline $\mathrm{P}_{i} \mathrm{C}_{i} \mathrm{~N}_{i}$ & 35.5 & 9.7 & 1.63 & 1.64 \\
\hline $\mathrm{N}_{i} \mathrm{C}_{i} \mathrm{P}_{i+1}$ & 99.8 & 15.2 & 1.66 & 1.66 \\
\hline \multicolumn{5}{|c|}{ Dihedral $U_{d}$} \\
\hline & \multicolumn{2}{|c|}{$K_{\varphi}\left(\mathrm{kcal} / \mathrm{mol} / \mathrm{rad}^{2}\right)$} & \multicolumn{2}{|c|}{$\varphi_{0}(\mathrm{rad})$} \\
\hline & Para $_{\text {helical }}{ }^{a}$ & Para $_{\text {nonhelical }} b$ & Para $_{\text {helical }}{ }^{a}$ & Para $_{\text {nonhelical }} b$ \\
\hline $\mathrm{P}_{i} \mathrm{C}_{i} \mathrm{P}_{i+1} \mathrm{C}_{i+1}$ & 2.8 & 1.1 & 2.56 & 2.51 \\
\hline $\mathrm{C}_{i-1} \mathrm{P}_{i} \mathrm{C}_{i} \mathrm{P}_{i+1}$ & 10.5 & 4.3 & -2.94 & -2.92 \\
\hline $\mathrm{C}_{i-1} \mathrm{P}_{i} \mathrm{C}_{i} \mathrm{~N}_{i}$ & 3.8 & 0.8 & -1.16 & -1.18 \\
\hline $\mathrm{N}_{i-1} \mathrm{C}_{i-1} \mathrm{P}_{i} \mathrm{C}_{i}$ & 4.2 & 0.7 & 0.88 & 0.78 \\
\hline \multicolumn{5}{|c|}{ Nonbonded } \\
\hline$r_{N N}(\AA)$ & 8.9 & & & 3.6 \\
\hline$r_{C N}(\AA)$ & 12.2 & & & 1.9 \\
\hline$r_{P N}(\AA)$ & 13.9 & & & 0.7 \\
\hline$\sigma_{s t}(\AA)$ & 4.8 & $\varepsilon_{b p}(\mathrm{k}$ & & -3.5 \\
\hline$r_{c s}(\AA)$ & 5.0 & $a(\mathrm{kcc}$ & & 0.4 \\
\hline \multicolumn{5}{|c|}{$\begin{array}{l}{ }^{a} \text { The Para }{ }_{\text {helical }} \text { are only used in the processes of folded structure refinement for the } \\
\text { base-pairing regions (stems) in the initially folded structure. }{ }^{b} \text { The Para }{ }_{\text {nonhelical }} \text { are used } \\
\text { in RNA folding processes to possibly describe RNAs as free chains. }\end{array}$} \\
\hline
\end{tabular}


Table B. The 17 RNA pseudoknots for 3D structure prediction used in this work.

\begin{tabular}{|c|c|c|c|c|c|c|c|}
\hline $\mathrm{RNAs}^{a}$ & PDB ID & $\begin{array}{c}\text { Length } \\
\text { (nt) }\end{array}$ & $\begin{array}{c}\text { L_Stem } 1^{b} \\
\text { (bp) }\end{array}$ & $\begin{array}{c}\text { L_Stem } 2^{c} \\
\text { (bp) }\end{array}$ & $\begin{array}{c}\text { L_Loop } 1^{d} \\
(\mathrm{nt})\end{array}$ & $\begin{array}{c}\mathrm{L}_{-} \text {Loop } 2^{e} \\
(\mathrm{nt})\end{array}$ & $\begin{array}{c}\text { L_Loop } 3^{f} \\
\text { (nt) }\end{array}$ \\
\hline 1 & $2 \mathrm{~g} 1 \mathrm{w}$ & 22 & 4 & 3 & 1 & 5 & 1 \\
\hline 2 & $1 \mathrm{a} 60$ & 23 & 3 & 5 & 4 & 3 & 0 \\
\hline 3 & $2 \mathrm{a} 43$ & 26 & 4 & 3 & 2 & 9 & 1 \\
\hline 4 & 2rp1 & 27 & 5 & 3 & 2 & 8 & 1 \\
\hline 5 & $112 x$ & 28 & 5 & 3 & 2 & 7 & 1 \\
\hline 6 & $1 \mathrm{kpy}$ & 28 & 5 & 3 & 2 & 8 & 1 \\
\hline 7 & 1yg4 & 28 & 5 & 3 & 2 & 9 & 1 \\
\hline 8 & $437 d$ & 28 & 5 & 3 & 2 & 7 & 1 \\
\hline 9 & 2ap5 & 28 & 5 & 3 & 2 & 9 & 1 \\
\hline 10 & $2 n 6 q$ & 31 & 5 & 7 & 2 & 5 & 0 \\
\hline 11 & $1 \mathrm{kpd}$ & 32 & 5 & 6 & 2 & 7 & 1 \\
\hline 12 & $1 \mathrm{rnk}$ & 34 & 5 & 7 & 1 & 8 & 1 \\
\hline 13 & $1 \mathrm{e} 95$ & 36 & 6 & 6 & 1 & 9 & 0 \\
\hline 14 & $2 \mathrm{tpk}$ & 36 & 5 & 7 & 1 & 7 & 0 \\
\hline 15 & 1 ymo & 47 & 6 & 9 & 8 & 8 & 0 \\
\hline 16 & $2 \mathrm{~m} 8 \mathrm{k}$ & 48 & 5 & 10 & 6 & 9 & 2 \\
\hline 17 & $21 \mathrm{c} 8$ & 56 & $11^{g}$ & 7 & 1 & 13 & 0 \\
\hline
\end{tabular}

${ }^{a}$ For each RNA pseudoknot, PDB ID, chain length and the length of two stems (Stem 1 and Stem 2) and three loops (Loop 1, Loop 2 and Loop 3) are listed. ${ }^{b, c, d, e, f}$ The length of Stem 1, Stem 2, Loop 1, Loop 2, and Loop 3 (see Fig. 1 in the maintext), respectively. ${ }^{g}$ Stem 1 of the pseudoknot (PDB ID: 2lc8) is interrupted by a bulge and an internal loop. 
Table C. The RMSDs of 3D structures of RNA pseudoknots predicted by the present model with and without the coaxial stacking potential.

\begin{tabular}{|c|c|c|c|c|c|}
\hline \multirow[t]{3}{*}{ RNAs } & \multirow{3}{*}{$\begin{array}{l}\text { PDB } \\
\text { ID }\end{array}$} & \multirow{3}{*}{$\begin{array}{l}\text { Length } \\
\text { (nt) }\end{array}$} & \multirow{3}{*}{$\begin{array}{c}\text { Coaxial stacking in } \\
\text { experimental structures }\end{array}$} & \multicolumn{2}{|c|}{ Mean $\operatorname{RMSD}^{b}(\AA)$} \\
\hline & & & & The present model & The present model \\
\hline & & & & with $U_{\mathrm{cs}}$ & without $U_{\mathrm{cs}}$ \\
\hline 1 & $2 \mathrm{~g} 1 \mathrm{w}$ & 22 & Yes & 5.3 & 6.2 \\
\hline 2 & $1 \mathrm{a} 60$ & 23 & Yes & 3.6 & 4.3 \\
\hline 3 & $2 \mathrm{a} 43$ & 26 & No & 4.2 & 3.9 \\
\hline 4 & 2rp1 & 27 & No & 4.2 & 4.2 \\
\hline 5 & $112 x$ & 28 & No & 5.1 & 4.5 \\
\hline 6 & $1 \mathrm{kpy}$ & 28 & No & 4.3 & 4.4 \\
\hline 7 & $1 \mathrm{yg} 4$ & 28 & No & 5.4 & 5.1 \\
\hline 8 & $437 d$ & 28 & No & 5.2 & 4.5 \\
\hline 9 & 2ap5 & 28 & No & 5.6 & 5.1 \\
\hline 10 & $2 n 6 q$ & 31 & Yes & 6.4 & 6.9 \\
\hline 11 & $1 \mathrm{kpd}$ & 32 & Yes & 5.9 & 6.0 \\
\hline 12 & $1 \mathrm{rnk}$ & 34 & Yes & 5.9 & 6.2 \\
\hline 13 & $1 \mathrm{e} 95$ & 36 & Yes & 5.4 & 6.5 \\
\hline 14 & $2 \mathrm{tpk}$ & 36 & Yes & 4.4 & 5.7 \\
\hline 15 & 1ymo & 47 & Yes & 9.3 & 9.9 \\
\hline 16 & $2 \mathrm{~m} 8 \mathrm{k}$ & 48 & Yes & 8.9 & 9.7 \\
\hline 17 & $2 \mathrm{lc} 8$ & 56 & Yes & 7.4 & 8.2 \\
\hline \multicolumn{3}{|c|}{ Mean value } & & 5.6 & 6.0 \\
\hline
\end{tabular}

${ }^{a}$ For each pseudoknot, is the coaxial stacking between two stems observed in experimental structure? ${ }^{b}$ The mean RMSDs for 17 RNA pseudoknots between structures predicted by the present model with and without the coaxial stacking potential and the native structures. 
Table D. The melting temperatures $\left(T_{\mathrm{m} 1} \text { and } T_{\mathrm{m} 2}\right)^{a}$ of six RNA pseudoknots at high salt predicted by the present model with/without the coaxial stacking potential $\left(U_{\mathrm{cs}}\right)$.

\begin{tabular}{|c|c|c|c|c|}
\hline $\begin{array}{c}\text { RNA } \\
\text { pseudoknots }^{b}\end{array}$ & $\begin{array}{c}\text { Coaxial stacking in } \\
\text { experimental } \\
\text { structures }^{c}\end{array}$ & $\begin{array}{l}\text { Expt. }\left({ }^{\circ} \mathrm{C}\right) \\
T_{\mathrm{m} 1} / T_{\mathrm{m} 2}\end{array}$ & $\begin{array}{l}\text { The model with } U_{\mathrm{cs}} \\
\qquad T_{\mathrm{m} 1} / T_{\mathrm{m} 2}\left({ }^{\circ} \mathrm{C}\right)\end{array}$ & $\begin{array}{l}\text { The model without } U_{\mathrm{cs}} \\
\qquad T_{\mathrm{m} 1} / T_{\mathrm{m} 2}\left({ }^{\circ} \mathrm{C}\right)\end{array}$ \\
\hline MMTV & Yes & $73.5 / 95.0$ & 71.7/96.3 & $69.1 / 95.4$ \\
\hline $\mathrm{T} 2$ & Yes & 68.9/77.6 & $67.2 / 78.8$ & $63.0 / 78.0$ \\
\hline PEMV-1 & No & $60.1 / 79.1$ & $54.5 / 80.8$ & $46.2 / 79.8$ \\
\hline BWYV & No & 69.4/91.2 & $65.8 / 93.1$ & $54.9 / 92.4$ \\
\hline PLRV & No & $67.4 / 87.5$ & $66.3 / 85.3$ & $59.3 / 85.6$ \\
\hline ScYLV & No & $67.5 / 77.9$ & $66.2 / 80.2$ & $61.9 / 79.8$ \\
\hline \multicolumn{5}{|c|}{$\begin{array}{l}{ }^{a} T_{\mathrm{m} 1} \text { and } T_{\mathrm{m} 2} \text { are the melting temperatures for the transitions from folded (pseudoknot) state to } \\
\text { intermediate (hairpin) state and from intermediate state to unfolded (coil) state, respectively. }{ }^{b} \\
\text { MMTV and T2 pseudoknots are at } 1000 \mathrm{mM}\left[\mathrm{K}^{+}\right] \text {; PEMV-1, BWYV, PLRV and ScYLV } \\
\text { pseudoknots are at } 500 \mathrm{mM}\left[\mathrm{K}^{+}\right] .{ }^{c} \text { For each pseudoknot, is the coaxial stacking between two } \\
\text { stems observed in experimental structure? }\end{array}$} \\
\hline
\end{tabular}




\section{Supporting References}

1. Shi YZ, Wang FH, Wu YY, Tan ZJ. A coarse-grained model with implicit salt for RNAs: predicting 3D structure, stability and salt effect. J. Chem. Phys. 2014; 141: 105102.

2. Shi YZ, Jin L, Wang FH, Zhu XL, Tan ZJ. Predicting 3D structure, flexibility, and stability of RNA hairpins in monovalent and divalent ion solutions. Biophys. J. 2015; 109: 2654-2665.

3. Xia T, SantaLucia J, Burkand ME, Kierzek R, Schroeder SJ, Jiao X, Cox C, Turner DH. Thermodynamic parameters for an expanded nearest-neighbor model for formation of RNA duplexes with Watson-Crick base pairs. Biochemistry 1998; 37: 14719-14735.

4. Manning GS. The molecular theory of polyelectrolyte solutions with applications to the electrostatic properties of polynucleotides. Q. Rev. Biophys. 1978; 11: 179-246.

5. Tan ZJ, Zhang W, Shi YZ, Wang FH. RNA folding: structure prediction, folding kinetics and ion electrostatics. Adv. Exp. Med. Biol. 2015; 827: 143-183.

6. Tan ZJ, Chen SJ. Electrostatic correlations and fluctuations for ion binding to a finite length polyelectrolyte. J. Chem. Phys. 2005; 122: 044903.

7. Tan ZJ, Chen SJ. RNA helix stability in mixed $\mathrm{Na}^{+} / \mathrm{Mg}^{2+}$ solution. Biophys. J. 2007; 92: 3615-3632. 